\title{
Arginine methyltransferases mediate an epigenetic ovarian response to endometriosis
}

\author{
Claudia Baumann, Mark Olson ${ }^{1}$, Kai Wang ${ }^{1,+}$, Asgerally Fazleabas ${ }^{1,2}$ and \\ Rabindranath De La Fuente \\ Department of Physiology and Pharmacology, College of Veterinary Medicine, University of Georgia, \\ 501 D.W. Brooks Drive, Athens, Georgia 30602, USA, ${ }^{1}$ Department of Obstetrics, Gynecology and Reproductive \\ Biology, Michigan State University, Grand Rapids, Michigan 49534, USA and ${ }^{2}$ Department of Women's Health, \\ Spectrum Health System, Grand Rapids, Michigan 49341, USA
}

Correspondence should be addressed to R De La Fuente; Email: rfuente@uga.edu A Fazleabas; Email: asgi@hc.msu.edu

${ }^{\dagger} \mathrm{K}$ Wang is now at Department of Animal Science, Michigan State University, East Lansing, Michigan 48824, USA

\begin{abstract}
Endometriosis is associated with infertility and debilitating chronic pain. Abnormal epigenetic modifications in the human endometrium have recently been implicated in the pathogenesis of this condition. However, whether an altered epigenetic landscape contributes to pathological changes in the ovary is unknown. Using an established baboon endometriosis model, early-, and late-stage epigenetic changes in the ovary were investigated. Transcript profiling of key chromatin-modifying enzymes using pathway-focused PCR arrays on ovarian tissue from healthy control animals and at 3 and 15 months of endometriosis revealed dramatic changes in gene expression in a disease duration-dependent manner. Ingenuity Pathway Analysis indicated that transcripts for chromatin-remodeling enzymes associated with reproductive system disease and cancer development were abnormally regulated, most prominently the arginine methyltransferases CARM1, PRMT2, and PRMT8. Downregulation of CARM1 protein expression was also detected in the ovary, fully-grown oocytes and eutopic endometrium following 15 months of endometriosis. Sodium bisulfite sequencing revealed DNA hypermethylation within the PRMT8 promoter, suggesting that deregulated CpG methylation may play a role in transcriptional repression of this gene. These results demonstrate that endometriosis is associated with changes of epigenetic profiles in the primate ovary and suggest that arginine methyltransferases play a prominent role in mediating the ovarian response to endometriosis. Owing to the critical role of CARM1 in nuclear receptor-mediated transcription and maintenance of pluripotency in the cleavage stage embryo, our results suggest that epigenetic alterations in the ovary may have functional consequences for oocyte quality and the etiology of infertility associated with endometriosis.
\end{abstract}

Reproduction (2015) $\mathbf{1 5 0} 297-310$

\section{Introduction}

Endometriosis is a chronic inflammatory disease that affects $5-10 \%$ of women of reproductive age in the USA (Goldstein et al. 1980, Eskenazi \& Warner 1997). It is defined by the presence of ectopic, estrogen-sensitive, endometrium-like tissue lesions primarily in the pelvic peritoneum and ovaries. These lesions cause inflammatory responses associated with angiogenesis, scarring, neuronal infiltration, adhesions, and fibrosis (Berkley et al. 2005, Tokushige et al. 2006). Endometriosis is diagnosed as the underlying condition in $50-60 \%$ of women and teenage girls with pelvic pain (Eskenazi \& Warner 1997, Alvarez et al. 2012) and dramatically impairs the quality of life. Retrograde menstruation has historically been considered a primary risk factor for the development of the disease (Sampson 1927, Rock et al. 1982, Bulun 2009). However, reports also suggest that other etiological factors, such as in utero exposure to diethylstilbestrol, environmental exposure to endocrinedisrupting agents, low birth weight and dietary choices may play significant roles in the development of endometriosis (Missmer et al. 2004, Bulun 2009, Diamanti Kandarakis et al. 2009, Missmer et al. 2010). Accumulating evidence indicates that endometriosis is associated with aberrant transcriptional profiles in the eutopic endometrium of women and baboons resulting in dysregulation of critical signaling pathways (Kao et al. 2003, Burney et al. 2007, Afshar et al. 2013). Importantly, in some cases, abnormal gene expression patterns and altered epigenetic modifications, such as hypomethylation of $\mathrm{CpG}$ islands within promoter regions 
of steroid hormone receptors, have also been identified in endometriotic lesions (Wu et al. 2005, Kim et al. 2007, Xue et al. 2007a,b).

Endometriosis causes infertility in up to $50 \%$ of patients and affects $20-40 \%$ of women seeking infertility evaluation (Berube et al. 1998, Giudice 2010). The disease is associated with decreased pregnancy rates following IVF and recurrent pregnancy loss (Vercammen \& D'Hooghe 2000, Barnhart et al. 2002, De Hondt et al. 2005). However, the specific mechanisms involved in sub-fertility associated with this condition are not known. Importantly, the effects of short- and long-term endometriosis on ovarian physiology remain to be determined. Here, we present new evidence indicating that endometriosis is linked with altered patterns of ovarian gene expression and demonstrate that a prominent epigenetic pathway associated with oocyte quality and developmental potential is severely disrupted in primate females with induced endometriosis.

Both structural and genomic similarities between baboon and human chromatin domains highlight the significance of the non-human primate model for the analysis of epigenetic modifications in this disease (Foret et al. 2014). Using an established baboon endometriosis induction model, we demonstrate changes in the ovarian epigenetic landscape in response to early and late stages of this condition. Comparative transcript profiling in ovaries from healthy control animals and following endometriosis induction revealed dramatic changes in the expression levels of key chromatin-modifying enzymes, suggesting a specific epigenetic response to endometriosis in the ovary. Importantly, our results indicate that reduced expression of arginine methyltransferases in oocytes and granulosa cells may be a major contributing factor to the etiology of endometriosisassociated infertility.

\section{Materials and methods}

\section{Animal husbandry and tissue collection}

Adult baboons were obtained from the Southwest National Primate Center (San Antonio, TX, USA) and housed in individual cages in the Biological Research Laboratories of the University of Illinois. The animals consisted of normally cycling females ranging in age from 5 to 15 years and weighing between 12 and $20 \mathrm{~kg}$. Endometriosis was experimentally induced in females of reproductive age by i.p. inoculation with menstrual endometrium on day 1 or 2 of two consecutive menstrual cycles as described previously (Fazleabas et al. 2002, 2003). Disease progression was monitored in each animal by consecutive laparoscopies at 3, 6-7, 9-10, 12, and 15-16 months after inoculation. Laparoscopy and laparotomies were performed between days 9 and 11 post-ovulation, the mid-luteal stage of the baboon menstrual cycle, which coincides with the window of uterine receptivity (Fazleabas et al. 1999). The stage of the cycle was determined by measuring estradiol levels in daily blood draws to determine the day of ovulation as previously reported (Fazleabas et al. 1999). At each laparoscopy, the number of lesions was counted and changes within the pelvic cavity were documented by video recording (Fazleabas et al. 2003, Hastings et al. 2006). Three months following disease induction, significantly more red lesions were observed, while at 6 months following disease induction, significantly more blue lesions were present. During subsequent disease progression, similar levels of red, blue, chocolate, white, and mixed lesions were seen, although a trend towards more red lesions indicated that the disease was still active (Hastings et al. 2006). Following each laparoscopy, a laparotomy was performed and endometrial tissue (ranging from 0.5 to $1 \mathrm{~g}$ ) was obtained using an endometriectomy procedure (Fazleabas et al. 1999). Ovaries were collected post-mortem from healthy control animals and females with endometriosis that did not present ovarian endometrioma. All experimental procedures were approved by the Animal Care Committee of the University of Illinois, Chicago, IL, USA.

Preovulatory oocytes were collected from primate ovaries by follicle puncture post-mortem and cultured in minimal essential medium (MEM) supplemented with $3 \mathrm{mg} / \mathrm{ml}$ BSA (Sigma-Aldrich) and $10 \mu \mathrm{M}$ of the phosphodiesterase inhibitor milrinone (Sigma-Aldrich) to prevent germinal vesicle breakdown. Surrounding granulosa cells were gently removed by continuous pipetting. In vitro-matured oocytes were obtained following culture in fresh MEM/BSA medium supplemented with $5 \%$ fetal bovine serum (Hyclone, Logan, UT, USA) for $16 \mathrm{~h}$ under an atmosphere of $5 \% \mathrm{O}_{2}, 5 \% \mathrm{CO}_{2}$, and $90 \% \mathrm{~N}_{2}$ at $37{ }^{\circ} \mathrm{C}$ before transfer to a $2 \%$ paraformaldehyde (PFA), $0.1 \%$ Triton $\mathrm{X}-100$ fixative solution for $20 \mathrm{~min}$ at room temperature and blocking in $1 \mathrm{mg} / \mathrm{ml} \mathrm{BSA}, 0.01 \%$ Triton X-100 in PBS overnight at $4{ }^{\circ} \mathrm{C}$ as described previously (De La Fuente et al. 2004).

\section{Immunochemistry}

Endogenous protein was detected by immunohistochemistry on paraffin-embedded ovarian and uterine tissue sections obtained from animals following 15 months of endometriosis as well as from disease-free controls. Briefly, tissues were fixed in $4 \%$ PFA for $24 \mathrm{~h}$ before dehydration and paraffin embedding. Tissue sections $(5 \mu \mathrm{M})$ were placed on glass slides, deparaffinized and rehydrated through xylene (twice for $10 \mathrm{~min}$ ) and serial ethanol washes ( 2 min each in 100, 95, 70, 50, and 30\% ethanol). Epitopes were retrieved by incubation in boiling $10 \mathrm{mM}$ sodium citrate supplemented with $0.05 \%$ Tween 20 (Sigma-Aldrich) for $30 \mathrm{~min}$. Auto-fluorescence and unspecific antibody binding were inhibited by quenching in $0.1 \mathrm{M}$ glycine (Sigma-Aldrich) in double distilled water for $30 \mathrm{~min}$ and blocking in PBS supplemented with $5 \%$ adult bovine serum (Hyclone) and $0.1 \%$ Triton X-100 (Sigma-Aldrich) for $50 \mathrm{~min}$ at room temperature. Primary antibodies were diluted in blocking buffer and slides were incubated overnight at $4{ }^{\circ} \mathrm{C}$ before washing in PBS, $0.05 \%$ Tween 20, and secondary antibody exposure. Optimal primary and secondary antibody dilutions were determined empirically for each marker and applied as follows: a mouse monoclonal anti-CARM1 [3H2] antibody (Abcam Cambridge, MA, USA) at a dilution of 1:200, a polyclonal rabbit anti-histone $\mathrm{H} 3$ trimethylated at lysine 9 (H3K9me3, Abcam) at a dilution of 1:200, a rabbit polyclonal anti-DNA methyltransferase 1 (DNMT1) 
antibody (1:500, pATH52, a kind gift of Dr T Bestor), a goat polyclonal anti-poly(ADP-ribose) polymerase 1 (PARP1) antibody at a dilution of 1:400 (R\&D Systems, Minneapolis, MN, USA) and a mouse anti- $\beta$-tubulin antibody (1:500, SigmaAldrich). Secondary antibodies, Alexa-Fluor 488 or 555 conjugated goat anti-mouse IgG and Alexa-Fluor 488 or 555 goat anti-rabbit IgG, were purchased from Molecular Probes, Inc. (Eugene, OR, USA) and used at a 1:1000 dilution for $1 \mathrm{~h}$ at room temperature.

Immunocytochemistry of whole-mount baboon oocytes was performed on PFA-fixed ova by incubation in primary antibody (H3K9me3, 1:500; DNMT1, 1:500; and PARP1, 1:400) in $1 \mathrm{mg} / \mathrm{ml}$ BSA in PBS, $0.01 \%$ Triton X-100 (blocking buffer) at $4{ }^{\circ} \mathrm{C}$ overnight, followed by three 20-min washes in blocking buffer and immunological detection with the appropriate secondary antibodies at a dilution of 1:1000 for $1 \mathrm{~h}$ at room temperature. Slides were mounted in anti-fading medium supplemented with DAPI (Vectashield; Vector Laboratories, Burlingame, CA, USA), to counterstain chromatin and were examined on a Leica DMRE fluorescence microscope equipped with epifluorescence (Leica Microsystems, Inc.). Micrographs were captured with a Leica DFC 350F camera using Openlab 3.1.7 Image Analysis Software.

\section{RNA extraction and pathway-focused transcript profiling}

Gene expression analyses were conducted using pathwayfocused human PCR Arrays for Epigenetic Chromatin-Modifying Enzymes (SABiosciences, Valencia, CA, USA; Qiagen) allowing the simultaneous quantification of a panel of 84 mRNA transcripts encoding for key chromatin-modifying enzymes known to establish genomic DNA methylation (including de novo and maintenance DNMTs) as well as enzymes that regulate essential histone post-translational modifications, including histone acetylation, methylation, phosphorylation, and ubiquitination. mRNA was isolated from flash-frozen ovarian tissues obtained at the mid-secretory phase of the estrous cycle from control animals $(n=2)$ and female baboons following 3 months $(n=2)$ and 15 months $(n=2)$ of endometriosis using the Micro-FastTrack 2.0 mRNA Isolation Kit (Invitrogen). cDNA synthesis by reverse transcription was conducted using the $\mathrm{RT}^{2}$ PreAMP cDNA Synthesis Kit using primer pairs specific to this pathway. Quantitative real-time PCR was performed on a Roche Light Cycler 480 System using an instrument-specific $\mathrm{RT}^{2}$ qPCR Master Mix (SABiosciences, Qiagen) according to manufacturer's instructions. RT efficiency, qPCR performance, and cDNA quality were confirmed in arrayintegrate control reactions. Expression data were normalized to a series of internal housekeeping genes (Hprt1, Rpl13A, Gapdh, and $\beta$-actin). Data points were excluded from the analysis when expression levels of genes were below detectable limits. In addition, unspecific amplification as indicated by multiple peaks in melting curves due to lack of sequence homology between individual human and primate genes were observed for Aurora kinase B, CIITA, Dnmt3B, HDAC1, HDAC2, KDM4C, KAT2B, PRMT7, SETD6, and the housekeeping control B2M and were thus excluded from the analysis. Raw threshold cycle data between control ovaries and ovaries obtained from females with induced endometriosis were compared using $\mathrm{RT}^{2}$ Profiler PCR Array Data Analysis Software (SABiosciences, Qiagen) version 3.5 to conduct all $\Delta \Delta$ Ct-based fold-change calculations.

Ingenuity Pathway Analysis (IPA, Ingenuity Systems, Redwood City, CA, USA) was performed as described earlier (Zelenko et al. 2012). Briefly, gene symbols and fold change values of up- and downregulated genes were imported into IPA Software and the top resulting significantly regulated molecular and biological networks were identified followed by functional analysis of the data set and canonical pathway analysis.

\section{Sodium bisulfite genomic sequencing}

Sodium bisulfite genomic sequencing was conducted as described previously (Wang et al. 2009). Briefly, genomic DNA was isolated from ovarian samples of control animals $(n=6)$ and animals following 15 months of endometriosis $(n=5)$ using the DNeasy Blood and Tissue Kit (Qiagen) before bisulfite conversion (DNA methylation Gold Kit, Zymo Research, Irvine, CA, USA) and nested PCR amplification (two rounds of 35 cycles each) using the following primer pairs: 'outerF' $5^{\prime}$-TTATTYGGTTTAGTTTTTAGGAGAGA-3”; 'outerR' 5'-TCCAACCCAACCCCTCAACTAAAAC-3'; and 'innerF' 5'-GGTAGAAGTTGAGAGGA GTTGG-3'; 'innerR' 5'-ATTTTCCTCCCTTCTCATCTACTC-3'. Amplicons of two independent nested PCRs were mixed and subcloned via TOPO-TA Cloning Technology (Invitrogen). Twelve clones per sample were analyzed by genomic sequencing of the PRMT8 promoter region located -38 to +186 bp relative to the transcription start site. The average level of DNA methylation of each individual animal was considered a biological repeat and used for statistical analysis. Data were analyzed using an online Quantification Tool for Methylation Analysis (http://quma.cdb.riken.jp/) with open and filled circles describing unmethylated and methylated CpG sites respectively.

\section{Statistical analysis}

All experiments were conducted in three biological replicates, with the exception of PCR arrays, which were performed in duplicate biological replicates. Representative examples are shown. Gene expression levels in ovarian tissues were compared using SABiosciences' Software module to perform all $\Delta \Delta$ Ct-based fold-change calculations from raw threshold cycle data. ANOVA and pair-wise comparison ( $t$-test) between groups of experimental replicates was conducted to define the fold up or downregulation and statistically significant thresholds $(P<0.05)$. $t$-Test analysis was also used to determine statistically significant differences in DNA methylation patterns by bisulfite genomic sequencing. Differences were considered significant when $P<0.05$.

\section{Results}

Transcriptionally repressive marks at centromeric heterochromatin are highly conserved in the primate oocyte genome

Aberrant epigenetic regulation of chromatin structure and function is increasingly recognized as a major contributor to the development of male and female 
infertility. However, little is known regarding epigenetic pathways and regulators that are potentially involved in the etiology of infertility during endometriosis. Interestingly, histone post-translational modifications show a remarkable degree of conservation among mammals (Cowell et al. 2002, Woo \& Li 2012). Yet, the patterns of expression and chromosomal localization of H3K9me3, a histone modification essential for heterochromatin formation and genome stability, in primate oocytes are not known. Therefore, we initially determined whether the centromeric localization of this prominent histone mark is conserved in the baboon ovary. In primordial, primary as well as early pre-antral follicles, surrounding ovarian granulosa cells exhibit prominent nuclear staining while the emerging theca cell layer exhibits only basal fluorescence (Fig. 1A and B, arrows). Notably, $\mathrm{H} 3 \mathrm{~K} 9 \mathrm{me} 3$ is highly enriched in the ovarian surface epithelium (Fig. 1A, arrowhead). Analysis of H3K9me3 localization at different stages of oocyte growth and differentiation revealed the presence of prominent nuclear foci associated with bright DAPI staining in the majority of oocytes from pre-antral follicles. Notably, several H3K9me3 foci were found in close apposition with the nucleolus (Fig. 2A, arrow). To determine whether $\mathrm{H} 3 \mathrm{~K} 9 \mathrm{me} 3$ is associated with heterochromatin domains, we compared the distribution of this chromatin mark in pre-ovulatory oocytes from adult females (Fig. 2B). Consistent with our previous observations, H3K9me3 exhibits a focal localization to heterochromatin domains in oocytes at the non-surrounded GV (NSN-GV) stage, exhibiting decondensed chromatin (Fig. 2B, top panel). Notably, the perinucleolar heterochromatin rim of the condensing nucleolus in surrounded nucleolus GV stage oocytes (SN-GV) presents bright $\mathrm{H} 3 \mathrm{~K} 9 \mathrm{me} 3$ associated with the nascent karyosphere (Fig. 2B, middle panel). In addition, this histone modification is prominent in the centromeres of condensing chromosomes following germinal vesicle breakdown (Fig. 2B, bottom panel). Together, our results indicate that $\mathrm{H} 3 \mathrm{~K} 9 \mathrm{me} 3$ association with condensed heterochromatin is conserved between mouse and primate ovarian somatic cells and oocytes. These results also demonstrate that $\mathrm{H} 3 \mathrm{~K} 9 \mathrm{me} 3$ is a prominent epigenetic mark in granulosa cells of primary and early pre-antral follicles in the baboon ovary at both the follicular and luteal stage of the estrous cycle.

\section{Endometriosis is associated with global changes in gene expression of chromatin-modifying enzymes in the ovary}

Altered gene expression profiles in the eutopic endometrium and endometrial lesions in patients with endometriosis as well as in animal models of this disease (Gui et al. 1999, Hapangama et al. 2010, Colon-Diaz et al. 2012, Khan et al. 2012, Afshar et al. 2013) have been linked to altered epigenetic chromatin modifications such as DNA methylation at critical promoter regions (Nasu et al. 2011) and changes in the patterns of specific histone modifications (Kawano et al. 2011, Monteiro et al. 2014). However, whether endometriosis impacts the epigenetic landscape in the ovary, resulting in dysregulation of gene expression, is unclear. In addition, little is known regarding the underlying molecular mechanisms eliciting altered epigenetic modifications in endometriosis. To determine the mechanisms involved in the establishment of abnormal epigenetic profiles we compared the patterns of gene expression of key chromatin remodeling enzymes in ovaries of healthy control baboons and animals with endometriosis using human pathway-focused PCR arrays. Transcript profiling of mRNA extracted from baboon ovaries during the luteal phase of the estrous cycle from controls and following 3 and 15 months following endometriosis induction, allowed the simultaneous analysis of 75 epigenetic chromatin-modifying enzymes. Pair-wise comparison of
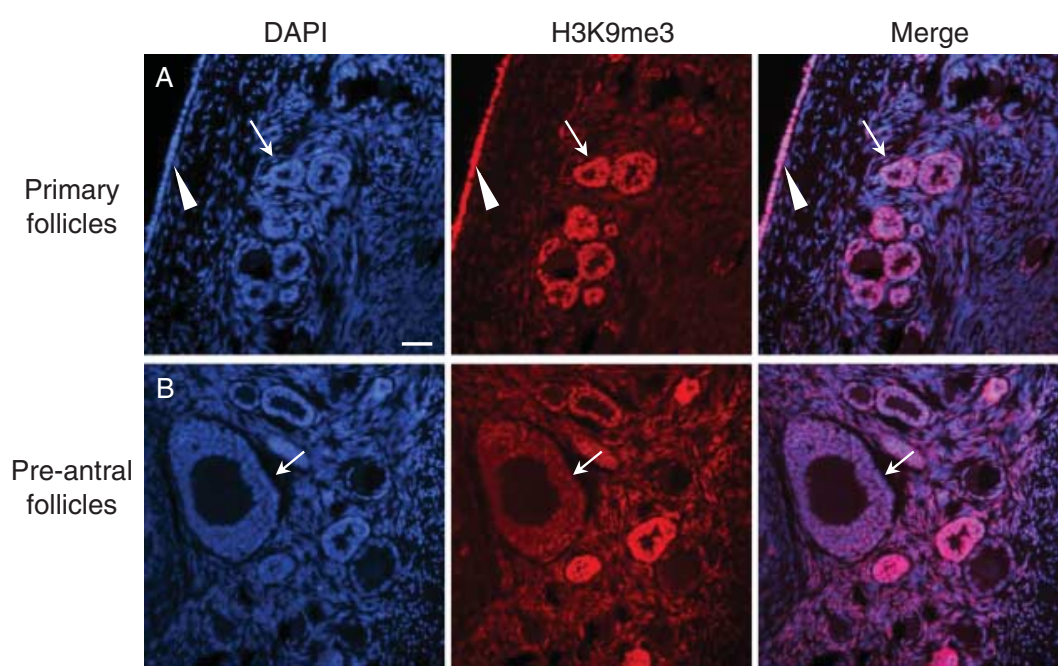

Figure 1 Prominent expression patterns of histone $\mathrm{H} 3$ trimethylated at lysine $9(\mathrm{H} 3 \mathrm{~K} 9 \mathrm{me} 3)$ in primate ovarian follicles. (A) $\mathrm{H} 3 \mathrm{~K} 9$ trimethylation is strongly detectable in granulosa cells of primary follicles (arrow) and the ovarian surface epithelium (arrowhead). (B) $\mathrm{H} 3 \mathrm{~K} 9 \mathrm{me} 3$ immunofluorescence intensity declines during follicular growth in pre-antral (arrow) and antral follicles (not shown). Scale bar $=10 \mu \mathrm{m}$. 
A

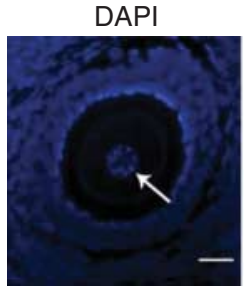

B
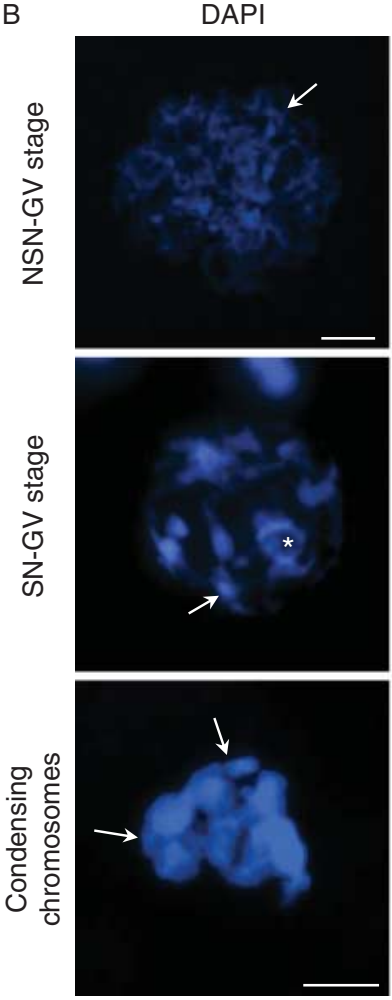

H3K9me3

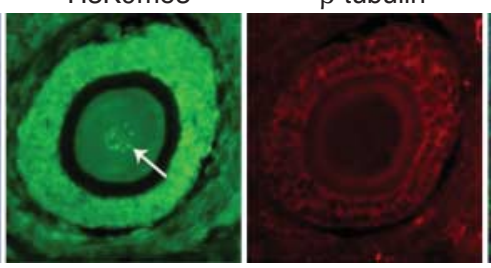

H3K9me3
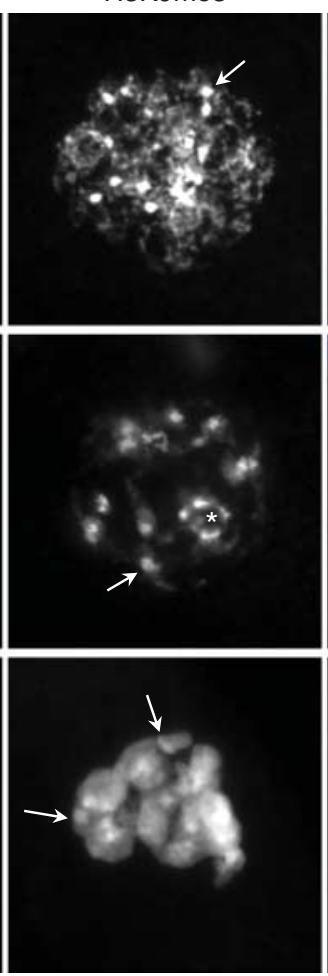

Merge

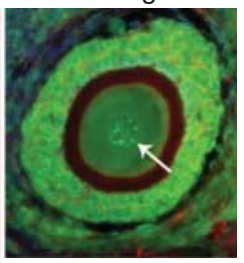

Merge
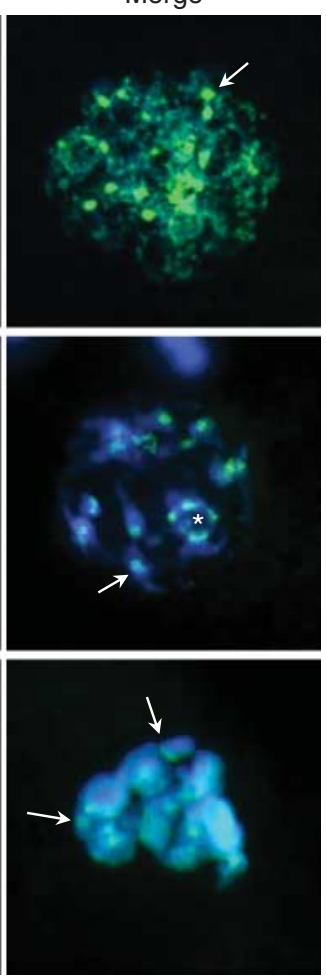

Figure 2 Conserved epigenetic heterochromatin marks in primate ovaries. (A) Immunolocalization of histone $\mathrm{H} 3$ lysine 9 trimethylation (H3K9me3, green) in baboon ovaries. Similar to the mouse, H3K9 trimethylation is distinctly detectable at heterochromatin domains within the oocyte nucleus (arrow). In addition, $\mathrm{H} 3 \mathrm{~K} 9 \mathrm{me} 3$ is a prominent marker of ovarian granulosa cells in this species. $\beta$-tubulin immunodetection (red) and the DNA dye DAPI (blue) were used as counterstains. Scale bar $=20 \mu \mathrm{m}$. (B) High-resolution micrographs of (top panel) NSN- and (middle panel) SN-GV stage oocyte nucleus of the baboon. Heterochromatin domains are immunolabeled with $\mathrm{H} 3 \mathrm{~K} 9 \mathrm{me} 3$ anti-

bodies (green, arrows). The position of the nucleolus is indicated by an asterisk (middle panel). (Lower panel) Centromeric heterochromatin of condensing chromosomes in baboon oocytes is detectable by $\mathrm{H} 3 \mathrm{~K} 9 \mathrm{me} 3$ immunolabeling (arrows). Scale bar $=10 \mu \mathrm{m}$. normalized, $\Delta \Delta$ Ct-based fold-change calculations between groups of experimental replicates was used to define the individual fold up- or downregulation in gene expression (Fig. 3A). No significant changes in gene expression between experimental groups were detected within the panel of housekeeping genes included in the arrays (ACTINB, GUSB, GAPDH, and HSP9OAB1). However, this analysis consistently revealed a trend towards a global decrease in the expression of chromatinmodifying enzymes in ovaries after 3 months of endometriosis compared to controls. Importantly, transcript downregulation was further exacerbated after 15 months of disease (Fig. 3A and B). Changes in gene expression greater than or equal to twofold were considered biologically significant and revealed a panel of six chromatin-modifying enzymes with significant $(P<0.05)$ downregulation after 3 months of endometriosis (ranging -2.1 - to -4.4 -fold; Table 1; highlighted in bold), while decreased transcript levels were detectable in 20 enzymes in samples obtained following
15 months of the disease (ranging -2.5 - to -17.8 -fold, Fig. 3A and Table 1 (highlighted in bold). Differences and similarities in transcript profiles among experimental groups are represented in the form of a Venn diagram (Fig. 3B). While transcript levels were unchanged for 69 of 75 genes between the control and the 3 months endometriosis group, altered transcript levels were detectable in 53 of 75 genes in the 15 months endometriosis group compared to the controls (Table 1 and Supplemental Table 1, see section on supplementary data given at the end of this article). At both experimental time points, the most prominent changes associated with endometriosis were evident in transcripts encoding protein arginine methyltransferases (Table 1). Specifically, 3 months following endometriosis induction, a significantly lower transcription level of PRMT8 (-4.4-fold) was noted in the baboon ovary, which was further reduced to -17.8 -fold after 15 months of the disease. A striking decline in gene expression was also detectable for PRMT2 (-5.8-fold) and the coactivator-associated 

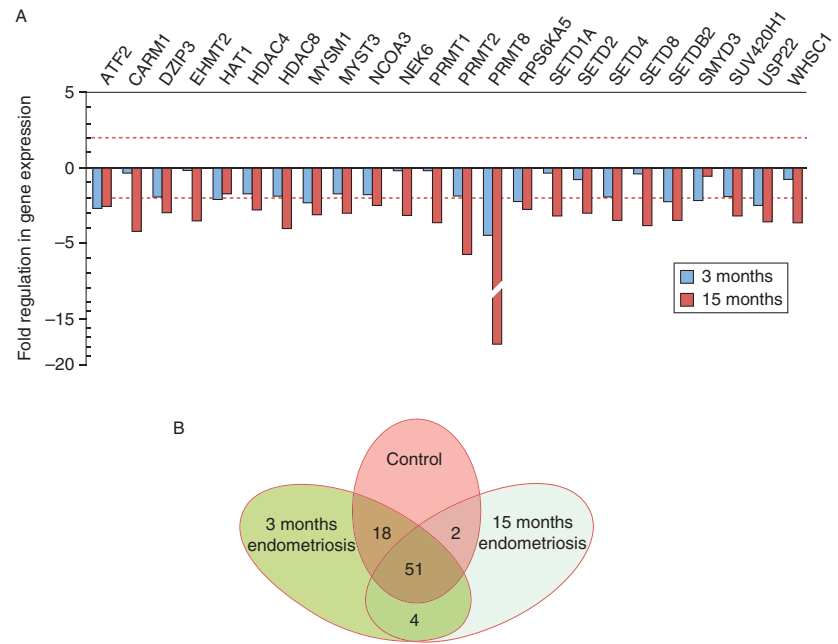

Figure 3 Endometriosis alters the gene expression levels of epigenetic chromatin remodeling enzymes in the baboon ovary. (A) Quantitative transcript profiling using pathway-focused PCR arrays revealed striking global changes in gene expression levels in response to 3 months of endometriosis in the majority of the 75 candidate genes tested (blue bars) as compared to disease-free control animals (normalization control). Differences in gene expression were found to be further exacerbated following a 15-month disease period (red bars).

(B) Venn diagram indicating differences and similarities in transcript levels between experimental groups and controls of a total of 75 genes analyzed.

arginine methyltransferase CARM1 (-4.2-fold) after 15 months of disease. Collectively, these results provide evidence that the presence of endometriotic lesions correlates with alterations in gene expression in the ovary and suggest a critical role of arginine methyltransferases in mediating this epigenetic ovarian response. IPA revealed gene expression, cell cycle, DNA replication, recombination, and DNA repair as the most significantly altered networks with an IPA score of 40. The top significantly regulated bio functions and associated diseases/disorders for the 3 months endometriosis group were cancer, reproductive system disease, hematological disease, endocrine system disorders, and gastrointestinal disease, while samples obtained 15 months following endometriosis induction revealed gene expression changes commonly involved in cancer, reproductive system disease, hematological disease, dermatological disease, and inflammatory disease (Table 2). These results highlight critical molecular changes in the ovary, which may contribute to the characteristic physiological changes associated with infertility, cancer predisposition and inflammatory disease in women with endometriosis.

\section{Endometriosis alters the DNA methylation pattern within the promoter region of the arginine methyltransferase PRMT8 gene}

DNA methylation at promoter sites plays an essential role in the regulation of gene expression. While hypomethylation is generally associated with a relaxed chromatin configuration, transcript overexpression and genome instability, DNA hypermethylation is known to result in transcriptional silencing through acquisition of epigenetic repressors and inhibition of transcription factor binding (Suzuki \& Bird 2008). To gain mechanistic insight into the differential expression patterns of arginine methyltransferases in response to endometriosis, we conducted sodium bisulfite sequencing of genomic DNA extracted from ovarian samples from controls $(n=6)$ and baboons following 15 months of endometriosis induction $(n=5)$. A specific promoter region containing $23 \mathrm{CpG}$ dinucleotides $(-38$ to +186 relative to the transcription start point of PRMT8) was investigated and significant $(P<0.05)$ hypermethylation was detectable in $\mathrm{CpG}$ dinucleotide 8 in samples collected from animals with endometriosis (Fig. 4) compared to controls. These data provide critical insight into the potential molecular basis of transcriptional repression of PRMT8 by an epigenetic mechanism involving PRMT8 promoter hypermethylation in ovaries from baboons with endometriosis.

\section{Effects of endometriosis on histone and DNMT enzymes in the endometrium and ovary}

The arginine methyltransferase CARM1 is implicated in the regulation of gene expression and is thought to play a critical role in mammalian development, cell proliferation, and differentiation (Chen et al. 1999, Wysocka et al. 2006, Torres-Padilla et al. 2007). CARM1 levels in the baboon endometrium (Fig. 5A, green) and ovary (Fig. 5B, green) were examined by immunohistochemistry using specific antibodies against CARM1. CARM1 protein labeling (green) varied prominently in samples collected from animals at different stages of the estrous cycle in both tissue types. Strong immunoreactivity was detectable in samples collected from animals at the late proliferative/follicular and mid-secretory/midluteal phase (top and middle panels), while CARM 1 was notably reduced in samples of the late secretory/late luteal phase (lower panels, Fig. 5A and B). H3K9me3 immunostaining (red) served as experimental control and DNA was counterstained with DAPI. A distinctive staining pattern was observed in the endometrium where CARM1 was enriched in the cytoplasm of endometrial glands cells (Fig. 5A, arrows). In contrast, CARM1 showed ubiquitous staining and was detectable in the cytoplasm of fully-grown oocytes as well as in surrounding granulosa cells in the ovary (Fig. 5B, arrows). CARM1 also showed prominent staining of associated endothelial cells (Fig. 5B, arrowheads).

Next, we set out to test whether CARM1 transcript downregulation during endometriosis, as detected by PCR arrays, correlates with a reduction in CARM1 protein expression. Endometrial and ovarian sections from control animals and following 15 months of 
Table 1 Significant fold up-/downregulation in gene expression of chromatin-modifying enzymes following 3 and 15 months of endometriosis.

\begin{tabular}{|c|c|c|c|c|c|}
\hline Synonyms & Gene & $\begin{array}{l}\text { Control vs } \\
3 \text { months }\end{array}$ & $\begin{array}{l}P \text { value (control vs } \\
3 \text { months) }\end{array}$ & $\begin{array}{l}\text { Control vs } \\
15 \text { months }\end{array}$ & $\begin{array}{c}\boldsymbol{P} \text { value (control vs } \\
15 \text { months) }\end{array}$ \\
\hline CREBP1, CREB2, HB16, MGC111558, TREB7 & ATF2 & -2.6 & 0.0365 & -2.6 & 0.0495 \\
\hline PRMT4 & CARM1 & -0.3 & 0.5532 & -4.2 & 0.0025 \\
\hline $\begin{array}{l}\text { FLJ13327, FLJ57977, FLJ58022, FLJ58223, } \\
\text { KIAA0675, UURF2, hRUL138 }\end{array}$ & $D Z I P 3$ & -1.9 & 0.0318 & -3 & 0.0078 \\
\hline $\begin{array}{l}\text { BAT8, C6orf30, DKFZp686H08213, FLJ35547, } \\
\text { G9A, KMT1C, NG36, NG36, G9a }\end{array}$ & EHMT2 & -0.1 & 0.6066 & -3.5 & 0.0002 \\
\hline KAT1 & HAT1 & -2.1 & 0.0474 & -1.7 & 0.5445 \\
\hline HA6116, HD4, HDACA, HDACA, KIAAO288 & HDAC4 & -1.7 & 0.0177 & -2.8 & 0.0192 \\
\hline HDACL1, RPD3 & HDAC8 & -1.9 & 0.0716 & -4.1 & 0.0172 \\
\hline $\begin{array}{l}\text { 2ADUB, } 2 A D U B, D K F Z p 779 J 1554 \\
\text { DKFZp779J1721, KIAA1915, } \\
\text { RP4-592A1.1 }\end{array}$ & MYSM1 & -2.3 & 0.0417 & -3.1 & 0.0066 \\
\hline KAT6A, MGC167033, MOZ, RUNXBP2, ZNF220 & MYST3 & -1.7 & 0.0006 & -3 & 0.0328 \\
\hline $\begin{array}{l}\text { ACTR, AIB-1, AIB1, CAGH16, CTG26, KAT13B, } \\
\text { MGC141848, RAC3, SRC-3, SRC3, TNRC14, } \\
\text { TNRC16, TRAM-1 }\end{array}$ & NCOA3 & -1.7 & 0.0173 & -2.5 & 0.0148 \\
\hline 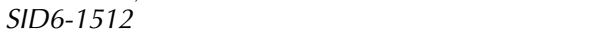 & NEK6 & -0.2 & 0.4369 & -3.2 & 0.0158 \\
\hline ANM1, HCP1, HRMT1L2, IR1B4 & PRMT1 & 0 & 0.6785 & -3.7 & 0.0463 \\
\hline HRMT1L1, MGC111373 & PRMT2 & -1.8 & 0.0211 & -5.8 & 0.0147 \\
\hline HRMT1L3, HRMT1L4 & PRMT8 & -4.4 & 0.0444 & -17.8 & 0.0012 \\
\hline MGC1911, MSK1, MSPK1, RLPK & RPS6KA5 & -2.2 & 0.0773 & -2.8 & 0.0293 \\
\hline KIAA0339, KMT2F, Set1, Set1A & SETD1A & -0.3 & 0.4835 & -3.2 & 0.0016 \\
\hline $\begin{array}{l}\text { FLJ16420, FLJ22472, FLJ23184, FLJ45883, } \\
\text { FLJ46217, HIF-1, HSPCO69, HYPB, KIAA1732, } \\
\text { KMT3A, SET2 }\end{array}$ & SETD2 & -0.7 & 0.431 & -3 & 0.0106 \\
\hline C21orf18, C21orf27 & SETD4 & -1.9 & 0.009 & -3.5 & 0.0064 \\
\hline KMT5A, PR-Set7, SET07, SET8 & SETD8 & -0.4 & 0.5172 & -3.8 & 0.0001 \\
\hline $\begin{array}{l}\text { C13orf4, CLLD8, CLLL8, DKFZp58610123, } \\
\text { DKFZp761J1217, KMT1F }\end{array}$ & SETDB2 & -2.2 & 0.0113 & -3.5 & 0.0018 \\
\hline $\begin{array}{l}\text { FLJ21080, MGC104324, ZMYND1, ZNFN3A1, } \\
\text { bA74P14.1 }\end{array}$ & SMYD3 & -2.1 & 0.0426 & -0.6 & 0.7016 \\
\hline $\begin{array}{l}\text { CGI-85, CGI85, KMT5B, MGC118906, } \\
\text { MGC118909, MGC21161, MGC703 }\end{array}$ & $\begin{array}{l}\text { SUV420- } \\
\text { H1 }\end{array}$ & -1.9 & 0.0619 & -3.2 & 0.0109 \\
\hline KIAA1063, USP3L & USP22 & -2.5 & 0.1012 & -3.6 & 0.0423 \\
\hline $\begin{array}{l}\text { FLJ23286, KIAA1090, MGC176638, MMSET, } \\
\text { NSD2, REIIBP, TRX5, WHS }\end{array}$ & WHSC1 & -0.7 & 0.4557 & -3.7 & 0.0027 \\
\hline
\end{tabular}

endometriosis were immunolabeled using CARM1 antibodies (green, Fig. 6). A striking downregulation of CARM1 was evident in the endometrium (Fig. 6A) and ovary (Fig. 6B) 15 months following endometriosis induction, while control tissues showed expression levels of CARM1 consistent with the mid-secretory/luteal stage of the estrous cycle. These results suggest that expression of CARM1 may be regulated in an estrous cycle-dependent manner. Importantly, these findings substantiate the notion that endometriosis is associated with a significant downregulation of CARM1 transcripts and protein.

DNMTs are responsible for establishment and maintenance of $\mathrm{CpG}$ methylation at regulatory sequences and play important roles in both genome stability and transcriptional mechanisms (Suzuki \& Bird 2008, Ha et al. 2011). Ectopic endometriotic lesions in women have been reported to show DNMT1, DNMT3A, and DNMT3B overexpression in comparison with the eutopic endometrium ( $\mathrm{Wu}$ et al. 2006). In addition, genomic DNA methylation patterns may also be affected by the loss of enzymatic activity of DNMT1 following non-covalent interactions with the DNA damage response protein PARP1 (Caiafa et al. 2009). PARP1 is a ubiquitously expressed nuclear protein (Doherty et al. 2002, Ratnam et al. 2002, Birt et al. 2013) involved in the maintenance of genome stability and cellular DNA damage response through proper poly(ADP-ribosyl)ation of histone molecules and other proteins (Ame et al. 2004, Vassena et al. 2005, Wu et al. 2006). Importantly, poly(ADP)-ribosylation can also be modulated in response to developmental or environmental stressors in order to regulate global chromatin remodeling processes (Kim \& Fazleabas 2004, Nezhat et al. 2014). Whether DNMTs and PARPs play a role in the ovarian epigenetic response to endometriosis is unknown. Therefore, ovarian sections obtained from controls and animals 3 and 15 months after disease induction were immunolabeled using specific antibodies against DNMT1 (green) and PARP1 (red, Fig. 7A). DNMT1 was expressed at very low levels in the cytoplasm of both primordial and primary oocytes from control ovaries 
Table 2 Significant bio functions.

\begin{tabular}{|c|c|c|}
\hline Diseases and disorders & $P$ value & $\begin{array}{c}\text { No. of } \\
\text { molecules }\end{array}$ \\
\hline \multicolumn{3}{|c|}{ Three months endometriosis } \\
\hline Cancer & $2.07 \times 10^{-4}-4.00 \times 10^{-2}$ & 6 \\
\hline $\begin{array}{l}\text { Reproductive system } \\
\text { disease }\end{array}$ & $3.27 \times 10^{-4}-3.30 \times 10^{-2}$ & 6 \\
\hline Hematological disease & $3.73 \times 10^{-4}-2.15 \times 10^{-2}$ & 7 \\
\hline Endocrine system disorders & $4.28 \times 10^{-4}-4.28 \times 10^{-4}$ & 6 \\
\hline Gastrointestinal disease & $4.28 \times 10^{-4}-2.31 \times 10^{-2}$ & 8 \\
\hline \multicolumn{3}{|l|}{15 months endometriosis } \\
\hline Cancer & $1.84 \times 10^{-14}-4.71 \times 10^{-2}$ & 22 \\
\hline $\begin{array}{l}\text { Reproductive system } \\
\text { disease }\end{array}$ & $2.15 \times 10^{-14}-4.52 \times 10^{-2}$ & 16 \\
\hline Hematological disease & $4.48 \times 10^{-14}-1.22 \times 10^{-2}$ & 18 \\
\hline Dermatological diseases & $3.99 \times 10^{-13}-1.84 \times 10^{-2}$ & 10 \\
\hline Inflammatory disease & $3.99 \times 10^{-13}-1.85 \times 10^{-6}$ & 9 \\
\hline
\end{tabular}

with some primordial follicles also exhibiting nuclear and nucleolar DNMT1 staining (arrowheads). However, no detectable differences were observed in the oocytes from ovaries with endometriosis. In contrast, prominent PARP1 staining was observed in the oocyte nucleus (arrowheads), nucleolus and the cytoplasm during the early stages of follicular growth and differentiation in primordial and primary oocytes as well as in follicular granulosa cells in control sections. Interestingly, induction of endometriosis resulted in increased PARP1 intensity in primordial and primary follicles following 15 months of disease (Fig. 7A).

We also compared the patterns of PARP1 and DNMT1 protein expression in fully-grown oocytes aspirated from ovarian follicles from control animals and following 15 months of endometriosis (Fig. 7B). At this stage of oocyte growth, DNMT1 is no longer detectable in the nucleus of baboon oocytes, but localizes diffusely to the cytoplasm, which is consistent with expression patterns in preovulatory mouse oocytes (Doherty et al. 2002, Ratnam et al. 2002). DNMT1 expression was noticeably increased in pre-ovulatory oocytes of animals following 15 months of endometriosis (lower panel). A similar increase in cytoplasmic PARP1 staining was observed in pre-ovulatory oocytes after 15 months of endometriosis. These data suggest an endometriosis-dependent upregulation of DNMT1 and PARP1 proteins in baboon oocytes and provide additional evidence for a complex epigenetic response to this condition in the female gonad.

\section{Discussion}

Endometriosis is a complex gynecological condition that develops spontaneously only in humans and nonhuman primates. The baboon model of induced endometriosis is a well-established animal model for the study of critical pathophysiological disease parameters in an environmentally controlled and replicable manner (De Hondt et al. 2005, Fazleabas 2006). Moreover,
(Woo \& Li 2012) this model system has provided valuable insight into disease aspects that are both remarkably similar and directly applicable to the study of endometriosis in women. For example, experimental induction of endometriosis in baboons leads to the development of endometriotic lesions that are morphologically and histologically indistinguishable from those found in women (Fazleabas et al. 2002, Harirchian et al. 2012). Both species exhibit identical disease characteristics, including subfertility (D'Hooghe et al. 1996, Fazleabas et al. 2002); and molecular studies in women and baboons with endometriosis suggest a strong conservation of the molecular pathways at play (Gui et al. 1999, Kim \& Fazleabas 2004, Burney et al. 2007, Afshar et al. 2013). However, little is known regarding changes in the ovarian epigenetic landscape in response to endometriosis, effects on oocyte quality, and any potential risks for transgenerational inheritance of epigenetic modifications induced by this condition in germ cells.

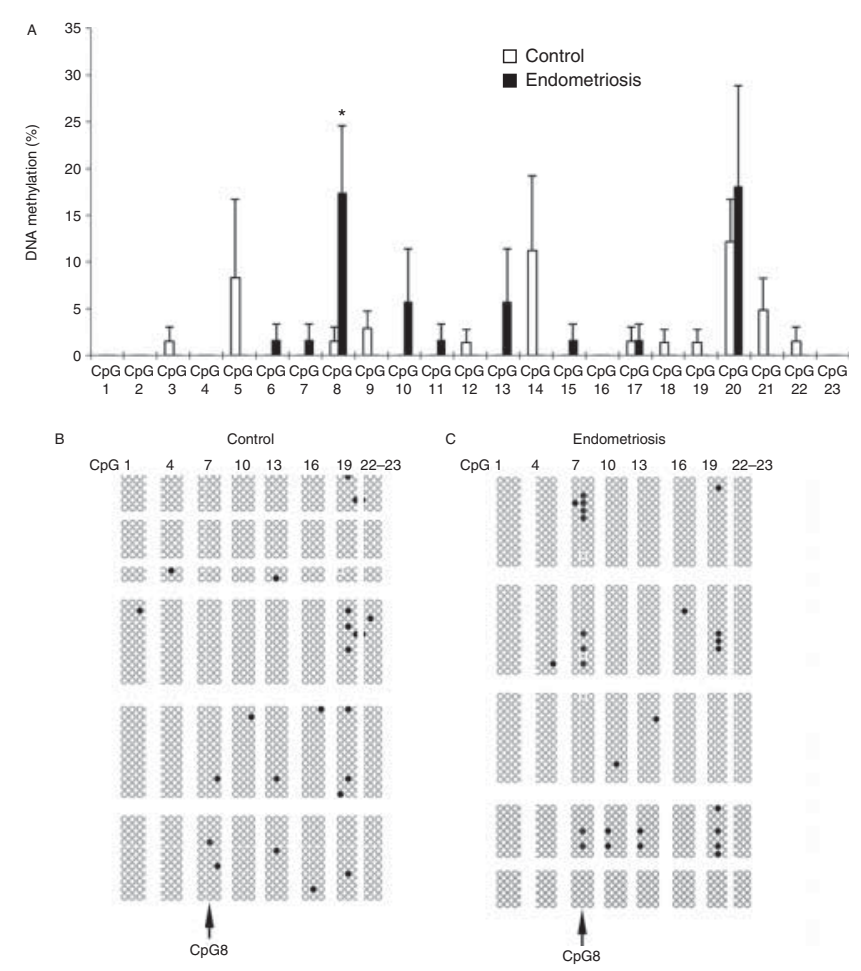

Figure 4 Alterations in DNA methylation patterns within the Prmt8 promoter region in response to endometriosis. (A) Analysis of Prmt8 promoter methylation patterns revealed a significant $(P<0.05)$ hypermethylation of CpG8 (asterisk) within the -38 to $+186 \mathrm{bp}$ region relative to the transcription start site following endometriosis (filled bars) compared to controls (open bars). Sodium bisulfite genomic sequencing spanning $23 \mathrm{CpG}$ dinucleotides within the primate Prmt8 promoter was conducted on controls (B) and ovaries following 15 months of endometriosis (C). Open circles indicate lack of DNA methylation while filled circles denote presence of DNA methylation. Each row represents an individual clone and clones are grouped according to samples from individual animals. 


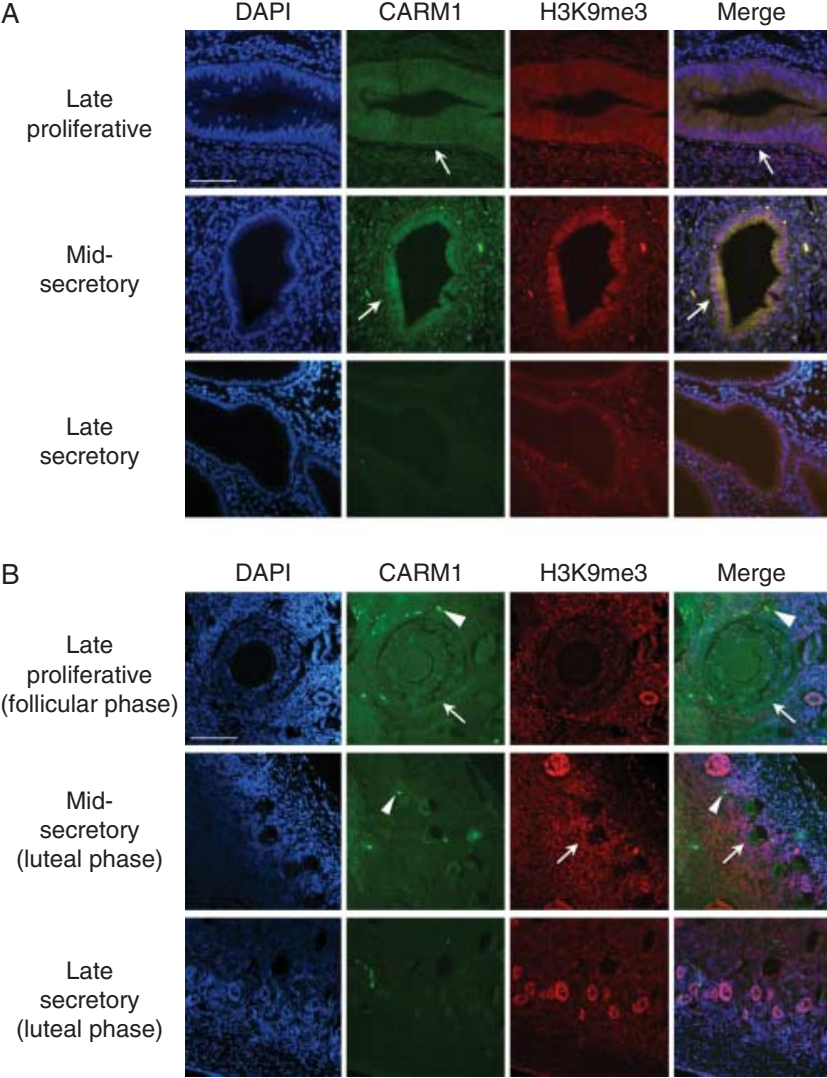

Figure 5 The arginine methyltransferase CARM1 levels vary in different estrous cycle stages in the baboon ovary and endometrium. Immunohistochemistry revealed strong immunoreactivity of CARM1 (green) in tissues at the late proliferative/follicular and mid-secretory/ mid-luteal stage in (A) endometrial as well as in ovarian sections (B). CARM1 is, in contrast, barely detectable in samples obtained at the late secretory/late luteal stage in the ovary and the endometrium (lower panels). H3K9me3 immunodetection was conducted as internal control and DNA was counterstained with DAPI. Scale bar $=100 \mu \mathrm{m}$.

We demonstrate here that aberrant gene expression is not restricted to ectopic endometrial lesions or the eutopic endometrium, but is extensively detectable in the ovaries of animals at different stages of the disease. Moreover, our data provide the first evidence that endometriosis is associated with significantly dysregulated expression patterns of key epigenetic factors in the ovary, which might contribute to the etiology and pathophysiology of endometriosis-associated infertility. A striking reduction in histone arginine methyltransferases PRMT2 and PRMT8 as well as CARM1 signal the early and long-term ovarian response to disease duration. Notably, the 17.8-fold downregulation in ovarian PRMT8 transcript levels is associated with hypermethylation of promoter sequences. In addition, both transcript and protein levels of CARM1 were significantly reduced in granulosa cells and pre-ovulatory oocytes after 15 months of endometriosis. Our findings provide critical insight into the potential mechanisms involved in the establishment of abnormal epigenetic modifications in both oocytes and granulosa cells during endometriosis. For example, arginine methyltransferases contribute to histone methylation, transcriptional regulation, and DNA repair (Bedford 2007). CARM1 plays a critical role in estrogen-dependent nuclear receptor mediated transcription in somatic cells (Bedford 2007) and maintenance of pluripotency in the mammalian preimplantation embryo (Torres-Padilla et al. 2007). Thus, disruption of the ovarian epigenetic landscape may have functional consequences for oocyte quality and the etiology of infertility associated with endometriosis.

A number of epigenetic aberrations, such as DNA hypermethylation of promoter regions (Wu et al. 2005, 2006, Nasu et al. 2011) as well as altered patterns of histone modifications (Kawano et al. 2011, Monteiro et al. 2014) have recently been identified in the eutopic and ectopic endometrium of women with endometriosis and provide critical insight into the role of epigenetic modifications in the regulation of aberrant gene expression in this disease. We extend upon these findings by demonstrating differential expression of an array of epigenetic chromatin-modifying enzymes in the baboon ovary following endometriosis induction. Increasing changes in transcript levels correlated with the duration of the disease indicate that gene expression changes during endometriosis may develop gradually,

A

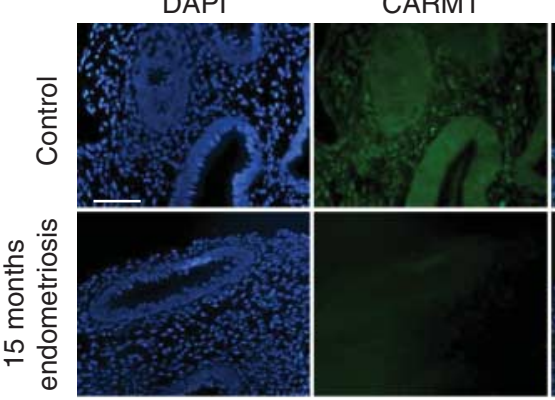

B
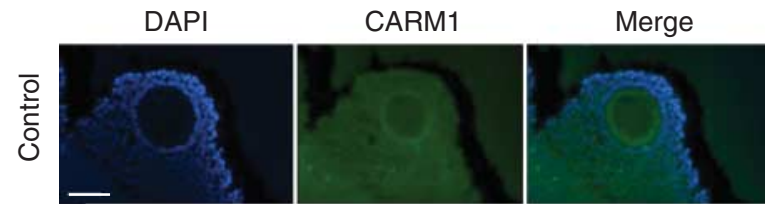

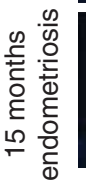
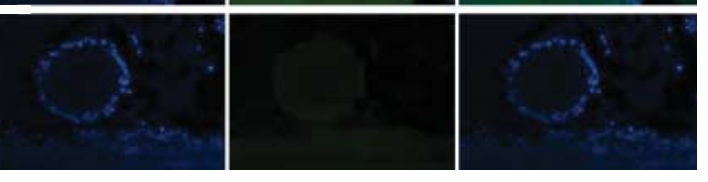

Figure 6 Endometriosis alters CARM1 levels in the ovary and endometrium. (A) CARM1 (green) is clearly detectable in mid-secretory endometrial sections obtained from control animals. By comparison, 15 months of endometriosis induce CARM1 downregulation and lead to reduced immunoreactivity (lower panel). (B) CARM1 is barely detectable in ovarian sections from animals following 15 months of endometriosis (lower panel) as compared to disease-free controls (upper panel). DNA is counterstained with DAPI. Scale bar $=50 \mu \mathrm{m}$. 


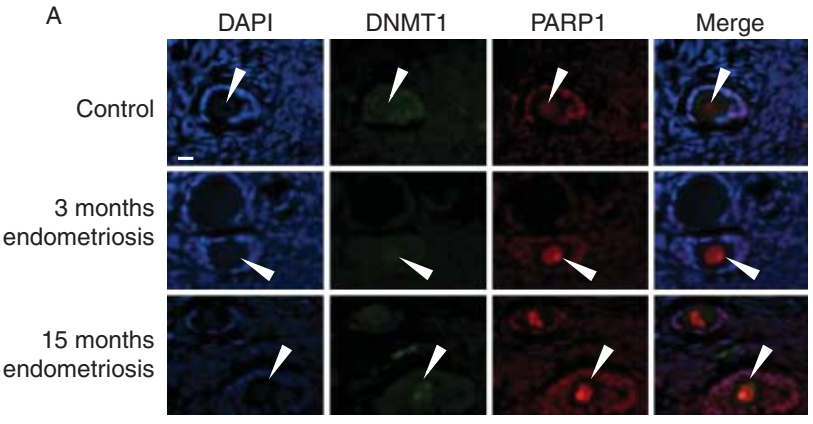

B

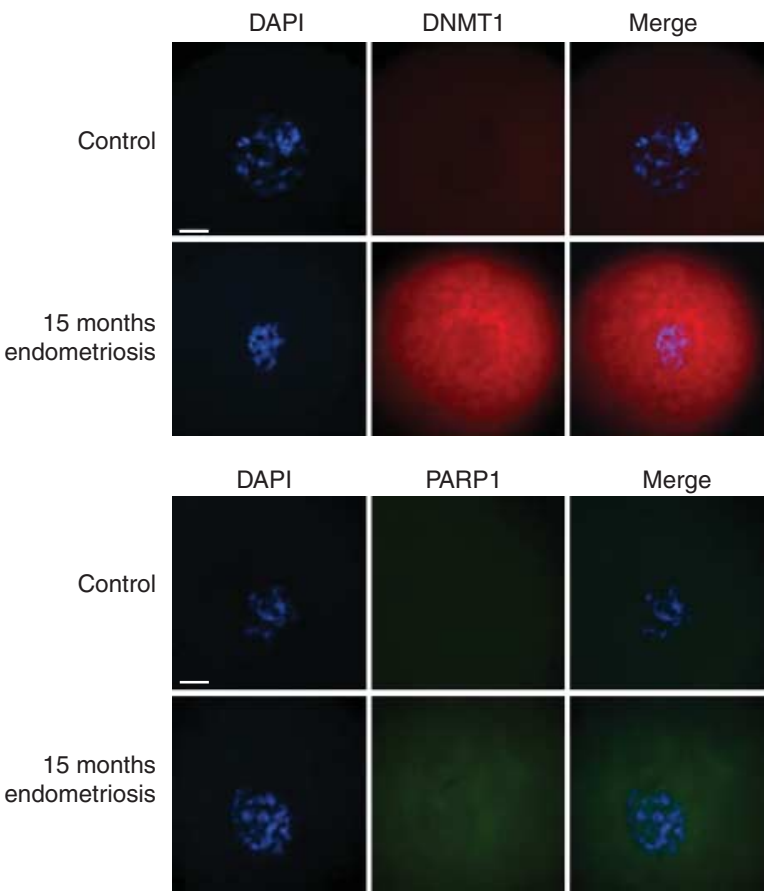

Figure 7 Global patterns of DNA methyltransferase (DNMT) DNMT1 and PARP1 in ovaries from animals with endometriosis. (A) Immunohistochemistry on paraffin sections obtained from control females (upper panel) and animals following 3 and 15 months of endometriosis (lower panels) indicates expression of the DNMTs DNMT1 (green) in the oocytes of primary and secondary follicles. PARP1 immunolabeling was prominently detected in nucleoli and nuclei as well as the granulosa cells of primary and early pre-antral follicles. Endometriosis burden for 15 months resulted in increased PARP1 labeling intensity. (B) Immunostaining of whole-mount oocytes with anti-DNMT1 and anti-PARP1 antibodies indicates diffuse cytoplasmic staining and an increase in DNMT1 in response to endometriosis compared to oocytes obtained from control animals. DNA is counterstained with DAPI (blue).

and show distinctive, stage-specific transcript profiles. Recent chronological expression data in the eutopic endometrium of baboons obtained by microarray analysis revealed an early disease burden and a transitory dominance of an estrogenic phenotype followed by a stable progesterone-resistant phenotype (Afshar et al. 2013), which is also found in human endometriosis (Burney et al. 2007). Intriguingly, the endometrial transcriptome 3 months following induction of disease showed a remarkable lack of differential gene expression (Afshar et al. 2013) similar to relatively limited gene expression changes detectable in the ovary at 3 months of endometriosis in our present study. Whether the ovarian transcriptome undergoes analogous stage-specific transitions remains to be investigated. However, evidence indicates that aberrant gene expression patterns in the eutopic endometrium are secondary to the disease and directly and acutely affected by endometriotic lesions rather than representing endometrium-inherent prerequisites for endometriosis (Afshar et al. 2013). Pathophysiological changes associated with the disease may likely also be responsible for abnormal gene expression in endometriotic ovaries. Thus, the identification of the precise molecular mechanisms that cause such striking epigenetic changes in the ovary will be a step of major importance.

In this study, members of the protein arginine $\mathrm{N}$-methyltransferase (PRMT) family of chromatinmodifying enzymes were among the most prominently altered genes identified by pathway-focused PCR arrays in ovaries of baboons at both 3 and 15 months following induction of endometriosis. Downregulation of CARM1 protein was confirmed by immunohistochemistry in the endometrium and ovary and revealed dynamic expression patterns according to the stage of the menstrual cycle with higher protein expression during the late proliferative and mid-secretory phase and negligible expression at the late secretory phase, suggesting regulatory effects of a cyclically changing hormonal environment consistent with CARM1's role in regulating estrogen receptor alpha $(E R \alpha)$ mediated gene pathways in response to $E R \alpha$ activation.

PRMTs play a crucial role in the dimethylation of arginine residues of many different target proteins. For instance, CARM1 and PRMT1 are co-activators of the tumor suppressor protein P53 through the specific methylation of arginine 17 in histone H3 (H3R17me2) and arginine 3 in histone 4 (H4R3me2) respectively. These histone modifications, in turn, are involved in facilitating p53-mediated transcriptional regulation (Scoumanne \& Chen 2008) and contribute to the control of cellular survival and tumor suppression. In addition, loss of CARM1 function alters the turnover of key molecules involved in cell cycle control, such as cyclin A, cyclin B1, c-fos, SIRT1, and p16 (Pang et al. 2013). Our data demonstrate significantly reduced transcription levels of CARM1, PRMT1, PRMT2, and PRMT8 in ovaries after 15 months of disease progression, suggesting dysregulation of arginine methyltransferases might predispose to the development of benign and premalignant disease characteristics such as impaired control of cell proliferation, clonal expansion of abnormal cells, and genome instability (Nezhat et al. 2014). Notably, IPA of samples obtained at 15 months following induction of endometriosis revealed gene expression changes commonly involved in inflammatory 
disease, reproductive system disease, and cancer. Taken together, these results support a hypothesis in which aberrant expression of key epigenetic chromatin-modifying enzymes may contribute to an oncogenic predisposition for specific subtypes of ovarian cancer (endometrioid and clear cell ovarian carcinoma) in individuals with endometriosis (Cheng et al. 2005). Although future studies will be necessary to substantiate this specific association, premalignant transformation following endometriosis is now considered a complex multifactorial process, triggered not only by genetic mutations (e.g., PTEN inactivation), but also epigenetic factors (e.g., aberrant expression of HOXA10) (Cheng et al. 2005) as well as environmental stimuli such as oxidative stress and pathologically elevated estrogen levels (Nezhat et al. 2014). Aberrant expression of PRMTs and other key epigenetic chromatin-modifying enzymes involved in nuclear receptor-mediated transcriptional regulation may be at the crossroads of these multifactorial stimuli, and thus further exacerbate a premalignant endometriotic phenotype.

Arginine methylation is also necessary for germ cell development in Drosophila (Anne 2010) and mice (Ancelin et al. 2006, Kim et al. 2014) and is dynamically regulated during mammalian oogenesis and preimplantation embryo development (Sarmento et al. 2004, Tee et al. 2010). Importantly, CARM1 is known to regulate the levels of histone $\mathrm{H} 3$ methylation at arginine (R17) and (R26) in blastomeres destined to give rise to the inner cell mass of the mouse pre-implantation embryo, and is required for the epigenetic control of pluripotency of embryonic stem cells (Torres-Padilla et al. 2007, Parfitt \& Zernicka-Goetz 2010). Our results demonstrate that endometriosis is associated with altered arginine methyltransferase expression and may thus interfere with PRMT-mediated ovarian estrogenregulated gene reprogramming and proper gametogenesis. For instance, CARM1-dependent methylation of H3R17 has protective effects on histone acetylation through the release of co-repressors from chromatin (Wu et al. 2012) and PRMT insufficiency may, in turn, interfere with proper histone acetylation. Notably, current evidence also suggests a prominent role for CARM1 in regulating the activity of the Notch family of transmembrane receptors through methylation of intracellular arginine residues (Hein et al. 2015). Notch signaling is crucial for many developmental processes such as cell differentiation and proliferation and has also recently been shown to play a critical role in decidualization of both mouse and human uterine stromal cells (Su et al. 2015). Loss of arginine methylation reduces Notch signaling, which is in turn associated with endometriosis and impaired decidualization (Hein et al. 2015, Su et al. 2015). Downregulation of CARM1 expression as observed in this study may thus provide further insight into the pathways involved in endometriosis-induced infertility.

Immunohistochemical analysis of ovarian sections and whole-mount oocytes revealed a striking upregulation of the maintenance methyltransferase DNMT1, which is in accordance with reports on DNMT overexpression in the ectopic endometrium in women with endometriosis $(\mathrm{Wu}$ et al. 2006). Dysregulated DNMT1 levels may alter DNA methylation at specific promoter regions influencing the transcriptional activity of target genes and could impact global chromatin methylation levels, thereby conferring susceptibility to genome instability and neoplastic transformation. Moreover, DNMT1 overexpression provides a potential link to promoter hypermethylation of the PRMT8 gene and the corresponding downregulation of PRMT8 expression following 15 months of endometriosis. Whether elevated PARP1 expression is induced in response to accumulating DNA damage in endometriotic tissues remains to be investigated in future experiments. However, IPA suggests a complex dysregulation of several canonical pathways and key molecules involved in cell cycle control, DNA replication, recombination, and repair that are commonly associated with neoplastic transformation and tumor progression as well as reproductive and endocrine system disorders in the ovary in response to endometriosis. Notably, both $\mathrm{H} 3 \mathrm{~K} 9 \mathrm{me} 3$ and PARP1 were highly expressed in the granulosa cells of primary and early pre-antral follicles, suggesting that changes in epigenetic modifications may be associated with follicular growth and differentiation. Thus, our findings provide the first account of an epigenetic ovarian response to the presence of endometriotic lesions and allow critical insight into the potential mechanisms disrupting epigenetic modifications in both oocytes and granulosa cells during the course of this disease.

Exposure to peritoneal fluid obtained from patients with endometriosis leads to aberrant chromosome alignment and spindle microtubule abnormalities in mouse metaphase II oocytes (Mansour et al. 2010). In addition, IVF cycles conducted with donor oocytes from women with endometriosis result in significantly lower pregnancy rates compared to tubal factor control donors irrespective of the recipient status, suggesting impaired germ cell quality prior to ovulation and exposure to peritoneal fluids (Barnhart et al. 2002, Mansour et al. 2010). Importantly, our findings suggest that the establishment of abnormal epigenetic modifications to both the somatic and germ cell compartment in the ovary during the course of endometriosis is a major contributing factor in the loss of fertility associated with this condition. The resulting epigenetic instability, aberrations in gene expression and compromised chromatin structure and function may ultimately be at the core of ovarian pathophysiology, reduced oocyte quality, subfertility, and potential transgenerational transmission of an altered epigenetic landscape following endometriosis.

In summary, our results demonstrate that endometriosis is correlated with altered levels of specific epigenetic chromatin-modifying enzymes that result in changes in the chromatin environment in the oocyte genome. This mechanism might predispose to potential 
transgenerational inheritance of abnormal epigenetic modifications established during oocyte growth. This notion is also supported by a recent report suggesting that endometriosis leads to heritable changes in gene expression in rat embryos over several generations (Birt et al. 2013). Our results demonstrate for the first time a link between endometriosis and a specific epigenetic ovarian response that may aid in identifying novel targets for epigenetic therapy to improve fertility and prevent any potential transgenerational inheritance of abnormal epigenetic modifications following endometriosis.

\section{Supplementary data}

This is linked to the online version of the paper at http://dx.doi. org/10.1530/REP-15-0212.

\section{Declaration of interest}

The authors declare that there is no conflict of interest that could be perceived as prejudicing the impartiality of the research reported.

\section{Funding}

This work was supported by NIH 2RO1-HD042740 and the Georgia Cancer Coalition to R De La Fuente and by the Eunice Kennedy Shriver NICHD through cooperative agreement U54 HD 40093 as part of the Specialized Cooperative Centers Program in Reproductive Research to A Fazleabas.

\section{Acknowledgements}

We would like to thank Dr Maria Viveiros for her critical reading of the manuscript.

\section{References}

Afshar Y, Hastings J, Roqueiro D, Jeong JW, Giudice LC \& Fazleabas AT 2013 Changes in eutopic endometrial gene expression during the progression of experimental endometriosis in the baboon, Papio anubis. Biology of Reproduction 88 44. (doi:10.1095/biolreprod.112.104497)

Alvarez P, Chen X, Hendrich J, Irwin JC, Green PG, Giudice LC \& Levine JD 2012 Ectopic uterine tissue as a chronic pain generator. Neuroscience 225 269-282. (doi:10.1016/j.neuroscience.2012.08.033)

Ame JC, Spenlehauer C \& de Murcia G 2004 The PARP superfamily. BioEssays: News and Reviews in Molecular, Cellular and Developmental Biology 26 882-893. (doi:10.1002/bies.20085)

Ancelin K, Lange UC, Hajkova P, Schneider R, Bannister AJ, Kouzarides T \& Surani MA 2006 Blimp1 associates with Prmt5 and directs histone arginine methylation in mouse germ cells. Nature Cell Biology 8 623-630. (doi:10.1038/ncb1413)

Anne J 2010 Arginine methylation of SmB is required for Drosophila germ cell development. Development 137 2819-2828. (doi:10.1242/dev. 052944)

Barnhart K, Dunsmoor Su R \& Coutifaris C 2002 Effect of endometriosis on in vitro fertilization. Fertility and Sterility 77 1148-1155. (doi:10.1016/ S0015-0282(02)03112-6)

Bedford MT 2007 Arginine methylation at a glance. Journal of Cell Science 120 4243-4246. (doi:10.1242/jcs.019885)
Berkley K, Rapkin A \& Papka R 2005 The pains of endometriosis. Science 308 1587-1589. (doi:10.1126/science.1111445)

Berube S, Marcoux S \& Maheux R 1998 Characteristics related to the prevalence of minimal or mild endometriosis in infertile women. Canadian Collaborative Group on Endometriosis. Epidemiology 9 504-510. (doi:10.1097/00001648-199809000-00006)

Birt JA, Taylor KH, Davis JW \& Sharpe-Timms KL 2013 Developmental exposure of fetal ovaries and fetal germ cells to endometriosis in an endometriosis model causes differential gene expression in the preimplantation embryos of the first-generation and second-generation embryos. Fertility and Sterility 100 1436-1443. (doi:10.1016/j.fertnstert. 2013.07.007)

Bulun S 2009 Endometriosis. New England Journal of Medicine 360 268-279. (doi:10.1056/NEJMra0804690)

Burney RO, Talbi S, Hamilton AE, Vo KC, Nyegaard M, Nezhat CR, Lessey BA \& Giudice LC 2007 Gene expression analysis of endometrium reveals progesterone resistance and candidate susceptibility genes in women with endometriosis. Endocrinology 148 3814-3826. (doi:10. 1210/en.2006-1692)

Caiafa P, Guastafierro T \& Zampieri M 2009 Epigenetics: poly(ADPribosyl)ation of PARP-1 regulates genomic methylation patterns. FASEB Journal 23 672-678. (doi:10.1096/fj.08-123265)

Chen D, Ma H, Hong H, Koh SS, Huang SM, Schurter BT, Aswad DW \& Stallcup MR 1999 Regulation of transcription by a protein methyltransferase. Science $\mathbf{2 8 4}$ 2174-2177. (doi:10.1126/science.284.5423.2174)

Cheng W, Liu J, Yoshida H, Rosen D \& Naora H 2005 Lineage infidelity of epithelial ovarian cancers is controlled by HOX genes that specify regional identity in the reproductive tract. Nature Medicine 11 531-537. (doi:10.1038/nm1230)

Colon-Diaz M, Baez-Vega P, Garcia M, Ruiz A, Monteiro JB, Fourquet J, Bayona M, Alvarez-Garriga C, Achille A, Seto E et al. 2012 HDAC1 and HDAC2 are differentially expressed in endometriosis. Reproductive Sciences 19 483-492. (doi:10.1177/1933719111432870)

Cowell IG, Aucott R, Mahadevaiah SK, Burgoyne PS, Huskisson N, Bongiorni S, Prantera G, Fanti L, Pimpinelli S, Wu R et al. 2002 Heterochromatin, HP1 and methylation at lysine 9 of histone $\mathrm{H} 3$ in animals. Chromosoma 111 22-36. (doi:10.1007/s00412-002-0182-8)

De Hondt A, Peeraer K, Meuleman C, Meeuwis L, De Loecker P \& D'Hooghe TM 2005 Endometriosis and subfertility treatment: a review. Minerva Ginecologica 57 257-267.

De La Fuente R, Viveiros M, Wigglesworth K \& Eppig J 2004 ATRX, a member of the SNF2 family of helicase/ATPases, is required for chromosome alignment and meiotic spindle organization in metaphase II stage mouse oocytes. Developmental Biology 272 1-14. (doi:10.1016/ j.ydbio.2003.12.012)

D'Hooghe TM, Bambra CS, Raeymaekers BM, Riday AM, Suleman MA \& Koninckx PR 1996 The cycle pregnancy rate is normal in baboons with stage I endometriosis but decreased in primates with stage II and stage III-IV disease. Fertility and Sterility 66 809-813.

Diamanti Kandarakis E, Bourguignon J-P, Giudice L, Hauser R, Prins G, Soto A, Zoeller RT \& Gore A 2009 Endocrine-disrupting chemicals: an Endocrine Society scientific statement. Endocrine Reviews 30 293-342. (doi:10.1210/er.2009-0002)

Doherty AS, Bartolomei MS \& Schultz RM 2002 Regulation of stagespecific nuclear translocation of Dnmt1o during preimplantation mouse development. Developmental Biology 242 255-266. (doi:10.1006/dbio. 2001.0534)

Eskenazi B \& Warner ML 1997 Epidemiology of endometriosis. Obstetrics and Gynecology Clinics of North America 24 235-258. (doi:10.1016/ S0889-8545(05)70302-8)

Fazleabas AT 2006 A Baboon Model for Inducing Endometriosis. In Placenta and Trophoblast Methods in Molecular Medicine ${ }^{\mathrm{TM}}$ Volume 121, 2006, pp 95-99.

Fazleabas AT, Donnelly KM, Srinivasan S, Fortman JD \& Miller JB 1999 Modulation of the baboon (Papio anubis) uterine endometrium by chorionic gonadotrophin during the period of uterine receptivity. PNAS 96 2543-2548. (doi:10.1073/pnas.96.5.2543)

Fazleabas AT, Brudney A, Gurates B, Chai D \& Bulun S 2002 A modified baboon model for endometriosis. Annals of the New York Academy of Sciences 955 308-317 (discussion 340-342, 396-406). (doi:10.1111/ j.1749-6632.2002.tb02791.x) 
Fazleabas AT, Brudney A, Chai D, Langoi D \& Bulun SE 2003 Steroid receptor and aromatase expression in baboon endometriotic lesions. Fertility and Sterility 80 (Suppl 2) 820-827. (doi:10.1016/S00150282(03)00982-8)

Foret MR, Sandstrom RS, Rhodes CT, Wang Y, Berger MS \& Lin CH 2014 Molecular targets of chromatin repressive mark H3K9me3 in primate progenitor cells within adult neurogenic niches. Frontiers in Genetics $\mathbf{5}$ 252. (doi:10.3389/fgene.2014.00252)

Giudice LC 2010 Endometriosis. New England Journal of Medicine 362 2389-2398. (doi:10.1056/NEJMcp1000274)

Goldstein D, deCholnoky C, Emans S \& Leventhal J 1980 Laparoscopy in the diagnosis and management of pelvic pain in adolescents. Journal of Reproductive Medicine 24 251-256.

Gui Y, Zhang J, Yuan L \& Lessey BA 1999 Regulation of HOXA-10 and its expression in normal and abnormal endometrium. Molecular Human Reproduction 5 866-873. (doi:10.1093/molehr/5.9.866)

Ha K, Lee GE, Palii SS, Brown KD, Takeda Y, Liu K, Bhalla KN \& Robertson KD 2011 Rapid and transient recruitment of DNMT1 to DNA double-strand breaks is mediated by its interaction with multiple components of the DNA damage response machinery. Human Molecular Genetics 20 126-140. (doi:10.1093/hmg/ddq451)

Hapangama DK, Turner MA, Drury J, Heathcote L, Afshar Y, Mavrogianis PA \& Fazleabas AT 2010 Aberrant expression of regulators of cell-fate found in eutopic endometrium is found in matched ectopic endometrium among women and in a baboon model of endometriosis. Human Reproduction 25 2840-2850. (doi:10.1093/humrep/deq248)

Harirchian P, Gashaw I, Lipskind ST, Braundmeier AG, Hastings JM, Olson MR \& Fazleabas AT 2012 Lesion kinetics in a non-human primate model of endometriosis. Human Reproduction 27 2341-2351. (doi:10.1093/humrep/des196)

Hastings JM, Jackson KS, Mavrogianis PA \& Fazleabas AT 2006 The estrogen early response gene FOS is altered in a baboon model of endometriosis. Biology of Reproduction 75 176-182. (doi:10.1095/ biolreprod.106.052852)

Hein K, Mittler G, Cizelsky W, Kuhl M, Ferrante F, Liefke R, Berger IM, Just S, Strang JE, Kestler HA et al. 2015 Site-specific methylation of Notch1 controls the amplitude and duration of the Notch1 response. Science Signaling 8 ra30. (doi:10.1126/scisignal.2005892)

Kao LC, Germeyer A, Tulac S, Lobo S, Yang JP, Taylor RN, Osteen K, Lessey BA \& Giudice LC 2003 Expression profiling of endometrium from women with endometriosis reveals candidate genes for disease-based implantation failure and infertility. Endocrinology 144 2870-2881. (doi:10.1210/en.2003-0043)

Kawano Y, Nasu K, Li H, Tsuno A, Abe W, Takai N \& Narahara H 2011 Application of the histone deacetylase inhibitors for the treatment of endometriosis: histone modifications as pathogenesis and novel therapeutic target. Human Reproduction 26 2486-2498. (doi:10.1093/humrep/der203)

Khan MA, Sengupta J, Mittal S \& Ghosh D 2012 Genome-wide expressions in autologous eutopic and ectopic endometrium of fertile women with endometriosis. Reproductive Biology and Endocrinology 1084. (doi:10.1186/1477-7827-10-84)

Kim JJ \& Fazleabas AT 2004 Uterine receptivity and implantation: the regulation and action of insulin-like growth factor binding protein-1 (IGFBP-1), HOXA10 and forkhead transcription factor-1 (FOXO-1) in the baboon endometrium. Reproductive Biology and Endocrinology 234. (doi:10.1186/1477-7827-2-34)

Kim JJ, Taylor HS, Lu Z, Ladhani O, Hastings JM, Jackson KS, Wu Y, Guo SW \& Fazleabas AT 2007 Altered expression of HOXA10 in endometriosis: potential role in decidualization. Molecular Human Reproduction 13 323-332. (doi:10.1093/molehr/gam005)

Kim S, Gunesdogan U, Zylicz JJ, Hackett JA, Cougot D, Bao S, Lee C, Dietmann S, Allen GE, Sengupta $\mathbf{R}$ et al. 2014 PRMT5 protects genomic integrity during global DNA demethylation in primordial germ cells and preimplantation embryos. Molecular Cell 56 564-579. (doi:10.1016/ j.molcel.2014.10.003)

Mansour G, Sharma R, Agarwal A \& Falcone T 2010 Endometriosis-induced alterations in mouse metaphase II oocyte microtubules and chromosomal alignment: a possible cause of infertility. Fertility and Sterility 94 1894-1899. (doi:10.1016/j.fertnstert.2009.09.043)

Missmer S, Hankinson S, Spiegelman D, Barbieri R, Michels K \& Hunter D 2004 In utero exposures and the incidence of endometriosis. Fertility and Sterility 82 1501-1508. (doi:10.1016/j.fertnstert.2004.04.065)
Missmer S, Chavarro J, Malspeis S, Bertone Johnson E, Hornstein M, Spiegelman D, Barbieri R, Willett W \& Hankinson S 2010 A prospective study of dietary fat consumption and endometriosis risk. Human Reproduction 25 1528-1535. (doi:10.1093/humrep/deq044)

Monteiro JB, Colon-Diaz M, Garcia M, Gutierrez S, Colon M, Seto E, Laboy J \& Flores I 2014 Endometriosis is characterized by a distinct pattern of histone 3 and histone 4 lysine modifications. Reproductive Sciences $\mathbf{2 1}$ 305-318. (doi:10.1177/1933719113497267)

Nasu K, Kawano Y, Tsukamoto Y, Takano M, Takai N, Li H, Furukawa Y, Abe W, Moriyama M \& Narahara H 2011 Aberrant DNA methylation status of endometriosis: epigenetics as the pathogenesis, biomarker and therapeutic target. Journal of Obstetrics and Gynaecology Research 37 683-695. (doi:10.1111/j.1447-0756.2011.01663.x)

Nezhat FR, Pejovic T, Reis FM \& Guo SW 2014 The link between endometriosis and ovarian cancer: clinical implications. International Journal of Gynecological Cancer 24 623-628. (doi:10.1097/IGC. 0000000000000100)

Pang L, Tian H, Chang N, Yi J, Xue L, Jiang B, Gorospe M, Zhang X \& Wang W 2013 Loss of CARM1 is linked to reduced HuR function in replicative senescence. BMCMolecular Biology 14 15. (doi:10.1186/1471-2199-14-15)

Parfitt DE \& Zernicka-Goetz M 2010 Epigenetic modification affecting expression of cell polarity and cell fate genes to regulate lineage specification in the early mouse embryo. Molecular Biology of the Cell 21 2649-2660. (doi:10.1091/mbc.E10-01-0053)

Ratnam S, Mertineit C, Ding F, Howell CY, Clarke HJ, Bestor TH, Chaillet JR \& Trasler JM 2002 Dynamics of Dnmt1 methyltransferase expression and intracellular localization during oogenesis and preimplantation development. Developmental Biology 245 304-314. (doi:10.1006/dbio.2002.0628)

Rock JA, Zacur HA, Dlugi AM, Jones HW \& TeLinde RW 1982 Pregnancy success following surgical correction of imperforate hymen and complete transverse vaginal septum. Obstetrics and Gynecology 59 448-451.

Sampson JA 1927 Metastatic or embolic endometriosis, due to the menstrual dissemination of endometrial tissue into the venous circulation. American Journal of Pathology 3 93-110.43.

Sarmento OF, Digilio LC, Wang Y, Perlin J, Herr JC, Allis CD \& Coonrod SA 2004 Dynamic alterations of specific histone modifications during early murine development. Journal of Cell Science 117 4449-4459. (doi:10. $1242 / j c s .01328)$

Scoumanne A \& Chen X 2008 Protein methylation: a new mechanism of p53 tumor suppressor regulation. Histology and Histopathology 23 11143-11149.

Su RW, Strug MR, Joshi NR, Jeong JW, Miele L, Lessey BA, Young SL \& Fazleabas AT 2015 Decreased Notch pathway signaling in the endometrium of women with endometriosis impairs decidualization. Journal of Clinical Endocrinology and Metabolism 100 E433-E442. (doi:10.1210/jc. 2014-3720)

Suzuki MM \& Bird A 2008 DNA methylation landscapes: provocative insights from epigenomics. Nature Reviews. Genetics 9 465-476. (doi:10.1038/nrg2341)

Tee WW, Pardo M, Theunissen TW, Yu L, Choudhary JS, Hajkova P \& Surani MA 2010 Prmt5 is essential for early mouse development and acts in the cytoplasm to maintain ES cell pluripotency. Genes and Development 24 2772-2777. (doi:10.1101/gad.606110)

Tokushige N, Markham R, Russell P \& Fraser I 2006 Nerve fibres in peritoneal endometriosis. Human Reproduction 21 3001-3007. (doi:10. 1093/humrep/del260)

Torres-Padilla ME, Parfitt DE, Kouzarides T \& Zernicka-Goetz M 2007 Histone arginine methylation regulates pluripotency in the early mouse embryo. Nature 445 214-218. (doi:10.1038/nature05458)

Vassena R, Dee Schramm R \& Latham KE 2005 Species-dependent expression patterns of DNA methyltransferase genes in mammalian oocytes and preimplantation embryos. Molecular Reproduction and Development 72 430-436. (doi:10.1002/mrd.20375)

Vercammen EE \& D'Hooghe TM 2000 Endometriosis and recurrent pregnancy loss. Seminars in Reproductive Medicine 18 363-368. (doi:10.1055/s-2000-13726)

Wang K, Chen Y, Chang EA, Knott JG \& Cibelli JB 2009 Dynamic epigenetic regulation of the Oct4 and Nanog regulatory regions during neural differentiation in rhesus nuclear transfer embryonic stem cells. Cloning and Stem Cells 11 483-496. (doi:10.1089/clo.2009.0019)

Woo YH \& Li WH 2012 Evolutionary conservation of histone modifications in mammals. Molecular Biology and Evolution 29 1757-1767. (doi:10. 1093/molbev/mss022) 
Wu Y, Halverson G, Basir Z, Strawn E, Yan P \& Guo SW 2005 Aberrant methylation at $\mathrm{HOXA} 10$ may be responsible for its aberrant expression in the endometrium of patients with endometriosis. American Journal of Obstetrics and Gynecology 193 371-380. (doi:10.1016/j.ajog.2005.01.034)

Wu Y, Strawn E, Basir Z, Halverson G \& Guo SW 2006 Promoter hypermethylation of progesterone receptor isoform B (PR-B) in endometriosis. Epigenetics 1 106-111. (doi:10.4161/epi.1.2.2766)

Wu J, Cui N, Wang R, Li J \& Wong J 2012 A role for CARM1-mediated histone $\mathrm{H} 3$ arginine methylation in protecting histone acetylation by releasing corepressors from chromatin. PLOS ONE 7 e34692. (doi:10. 1371/journal.pone.0034692)

Wysocka J, Allis CD \& Coonrod S 2006 Histone arginine methylation and its dynamic regulation. Frontiers in Bioscience 11 344-355. (doi:10.2741/1802)

Xue Q, Lin Z, Cheng Y-H, Huang C-C, Marsh E, Yin P, Milad M, Confino E, Reierstad S, Innes J et al. 2007a Promoter methylation regulates estrogen receptor 2 in human endometrium and endometriosis. Biology of Reproduction 77 681-687. (doi:10.1095/biolreprod.107.061804)
Xue Q, Lin Z, Yin P, Milad M, Cheng Y-H, Confino E, Reierstad S \& Bulun S $2007 b$ Transcriptional activation of steroidogenic factor- 1 by hypomethylation of the $5^{\prime} \mathrm{CpG}$ island in endometriosis. Journal of Clinical Endocrinology and Metabolism 92 3261-3267. (doi:10.1210/jc.20070494)

Zelenko Z, Aghajanova L, Irwin JC \& Giudice LC 2012 Nuclear receptor, coregulator signaling, and chromatin remodeling pathways suggest involvement of the epigenome in the steroid hormone response of endometrium and abnormalities in endometriosis. Reproductive Sciences 19 152-162. (doi:10.1177/1933719111415546)

Received 7 May 2015

First decision 4 June 2015

Revised manuscript received 25 July 2015

Accepted 29 July 2015 